\title{
Optimal Cut-Off Values of Visceral Fat Area for Predicting Metabolic Syndrome Among Type 2 Diabetes Patients in Ningbo, China
}

This article was published in the following Dove Press journal: Diabetes, Metabolic Syndrome and Obesity: Targets and Therapy

\author{
Xi Yang $\mathbb{D}^{1, *}$ \\ Yi Lin $\mathbb{D}^{2, *}$ \\ Guo-dong $\mathrm{Xu} \mathrm{Di}^{3}$ \\ Yan-shu Chen (iD) \\ Ye Zhou (iD) ${ }^{4}$ \\ Jing Sun $\mathbb{D I}^{5}$ \\ $\mathrm{Li} \mathrm{Li} \mathrm{(iD)}$
}

'Department of Nutrition, Ningbo First Hospital, Ningbo, Zhejiang Province, People's Republic of China; ${ }^{2}$ Center for Health Economics, School of Economics, Faculty of Humanities and Social Sciences, University of Nottingham, Ningbo,

Zhejiang Province, People's Republic of China; ${ }^{3}$ Department of Medical Records Statistics, Ningbo Medical Center Lihuili Hospital, Ningbo, Zhejiang Province, People's Republic of China; ${ }^{4}$ Department of Endocrinology and Metabolism, Ningbo First Hospital, Ningbo, Zhejiang Province, People's Republic of China; ${ }^{5}$ Menzies Health Institute Queensland and School of Medicine, Griffith University, Gold Coast, Queensland, Australia

*These authors contributed equally to this work
Correspondence: $\mathrm{Li} \mathrm{Li}$

Department of Endocrinology and Metabolism, Ningbo First Hospital, Ningbo, Zhejiang Province, People's

Republic of China

Tel +86 I375742 6626

Email lilyningbo@I63.com
Objective: To examine the optimal cut-off values of visceral fat area (VFA) for predicting metabolic syndrome (MetS) among type 2 diabetes (T2D) patients in Ningbo China.

Methods: A total of 1017 subjects were selected from T2D patients who accepted standardized management by the National Standardized Metabolic Disease Management Center at Ningbo First Hospital from March 2018 to January 2020. Demography and medical information were collected through questionnaires. Regional adiposity was examined by a visceral fat analyzer using the dual bioelectrical impedance method.

Results: Overall, 769 (75.6\%) T2D patients were defined to have MetS. Patients with MetS had higher anthropometric values and biomarkers, compared to those without MetS. VFA was significantly correlated with risk factors of MetS. Further logistic regression models showed that VFA was significantly associated with MetS in men $(\mathrm{OR}=1.02)$ and in women $(\mathrm{OR}=1.03) \quad(\mathrm{P}<0.001$ for both genders) after controlling for related factors. Receiveroperating characteristic curve analysis demonstrated that the optimal cut-off values of VFA were $84.7 \mathrm{~cm}^{2}$ for men and $81.1 \mathrm{~cm}^{2}$ for women to predict MetS in T2D patients.

Conclusion: VFA was associated with MetS and could be an independent predictor of MetS in T2D patients.

Clinical Trial Registration: www.ClinicalTrials.gov, number: NCT03811470.

Keywords: abdominal obesity, metabolic syndrome, visceral fat area, type 2 diabetes

\section{Introduction}

Metabolic syndrome (MetS) is a cluster of conditions that contribute to the risk of cardiovascular diseases (CVD), heart disease, stroke and type 2 diabetes (T2D), which may increase all-cause mortality. ${ }^{1,2}$ MetS involves at least three out of five metabolic conditions, including hypertension, glucose intolerance, abdominal obesity, decreased high-density lipoprotein cholesterol (HDL-C), and increased triglyceride (TG) levels. ${ }^{3,4}$ The prevalence of T2D and MetS has increased rapidly in China due to rapid economic development and urbanization. The prevalence of MetS in adults was $10.5 \%$ in 2009 and $14.4 \%$ in 2014 in China $^{5,6}$ based on the Chinese Diabetes Society (2004) criteria. $^{7}$

Abdominal obesity, evaluated by waist circumference (WC), is known to be a critical contributor to cardio-metabolic risk factors, ${ }^{8,9}$ but $\mathrm{WC}$ is not able to distinguish visceral fat from subcutaneous adipose tissues effectively. ${ }^{10}$ Instead, abdominal visceral fat has been considered to be a more associative cardiovascular risk factor of body fat distribution than BMI and WC. ${ }^{11-13}$ Previous studies showed 
that visceral fat area (VFA) was superior to BMI and WC to predict MetS and various cut-off values of VFA have been developed according to race, gender and age. ${ }^{14-17}$ The accurate assessment and management of visceral fat accumulation were suggested to be critical to identify the cardiovascular risks among patients with T2D. Recently, computed tomography (CT), magnetic resonance imaging and dual-energy X-ray absorptiometry were recognized as the accurate methods to evaluate the visceral adipose tissue. $^{18-20}$ However, due to the high cost of technology and high radiation exposure, these methods have been limited in clinical practice and have not been appropriate for screening purpose for a large population yet. In contrast, the dual current pathways bioelectrical impedance analysis (BIA) method was reported to measure central abdominal fat without X-ray exposure, with an accuracy for estimated VFA which was similar to the detection results of the X-ray CT method. ${ }^{20,21}$ Because of its simplicity, noninvasiveness and relatively low cost, abdominal BIA can be used as a potentially good alternative measure of visceral fat accumulation.

With aging, fat mass tends to accumulate in the abdomen, and the risk of chronic diseases such as diabetes and CVD have been dramatically increased. ${ }^{22,23}$ Previous studies have shown that the prevalence of MetS was higher in people with $\mathrm{T} 2 \mathrm{D},{ }^{24,25}$ and the cardiovascular mortality rate of subjects with metabolic syndrome was significantly increased regardless of the presence of T2D. ${ }^{24-27}$ Our previous research showed that the prevalence of MetS among adults in Ningbo was about $31 \%$, which has reached a similar prevalence level of MetS in adults worldwide $(20-30 \%){ }^{28}$ Therefore, establishment of an abdominal obesity assessment measure to accurately identify the risk of MetS and better control the risk of CVD in T2D is needed.

Up to date, few studies have examined the relationship between visceral fat and MetS in Chinese population. In addition, no study has explored the relationship between visceral fat and MetS in Chinese T2D patients. To fill in these research gaps, this study aimed to estimate optimal cut-off values of VFA and to investigate the risk of MetS among T2D patients in Chinese population.

\section{Patients and Methods}

\section{Subjects}

The present cross-sectional study recruited 1017 patients, diagnosed with T2D, aged from 18 to 75 years from
March 2018 to January 2020 at the outpatient department of the Endocrinology of Ningbo First Hospital, Zhejiang province, China and the National Standardized Metabolic Disease Management Center (MMC). In order to meet all the challenges of metabolic diseases, the MMC program was launched in $2016 .{ }^{29}$ In MMC, patients can enjoy one-stop care, from registration, testing, evaluation, prescription to health education, and a series of comprehensive services to achieve a more convenient and accurate patient care model. T2D was diagnosed based on the definition proposed by the World Health Organization. ${ }^{30}$ We defined diabetes as fasting plasma glucose $(\mathrm{FPG}) \geq 7.0 \mathrm{mmol} / \mathrm{L}(126 \mathrm{mg} / \mathrm{dl})$ or $2 \mathrm{~h}$ oral glucose tolerance test (OGTT) glucose $\geq 11.1 \mathrm{mmol} / \mathrm{L}$ (200 mg/dl). Subjects taking anti-diabetic drugs were also considered to have diabetes. The patients were excluded if they met any of the following criteria 1) age $>75$ years and age $<18$ years; 2) diagnosis with any kind of cancer; 3 ) positive islet autoantibodies; 4) glomerular filtration rate (eGFR) <30 mL/min; 5) severe liver dysfunction; 6) acute infectious diseases; 7) pregnancy or lactation.

The research project was approved by the Ethics Committee of Ningbo First Hospital, China (Ethics Approval No. 2019-R057) and followed the Declaration of Helsinki. Written informed consents were obtained from all participants.

\section{Definition of Metabolic Syndrome}

MetS was defined based on the 2017 Chinese Diabetes Society's (CDS) criteria. ${ }^{31}$ The diagnostic criteria of MetS is the presence of three or more of the medical components: 1) abdominal obesity: WC $>90 \mathrm{~cm}$ in men or $>85 \mathrm{~cm}$ in women; 2) hyperglycemia: FPG $\geq 6.1 \mathrm{mmol} / \mathrm{L}$ (110 mg/dl) or 2-hour postprandial plasma glucose ( $2 \mathrm{hPG}$ ) level $\geq 7.8$ (140 mg/dl) mmol/L or previously diagnosed with T2D; 3) hypertension: systolic blood pressure (SBP)/diastolic blood pressure $(\mathrm{DBP}) \geq 130 / 85 \mathrm{mmHg}$ or previously diagnosed with hypertension and receiving medical treatments; 4) $\mathrm{TG} \geq 1.7$ $\mathrm{mmol} / \mathrm{L}(150 \mathrm{mg} / \mathrm{dl}) ; 5) \mathrm{HDL}-\mathrm{C}<1.0 \mathrm{mmol} / \mathrm{L}(40 \mathrm{mg} / \mathrm{dl})$. Since all subjects were diagnosed with T2D, MetS is defined at least two of the above medical components with the exception for 2). Based on the criteria of MetS, all subjects were divided into two groups: MetS (-) (T2D patients with no MetS) and MetS (+) (T2D patients defined as MetS).

\section{Demographic and Clinical Characteristics}

All patients were invited to complete the MMC standard questionnaires on their demography, lifestyle [smoking status (currently no smoking and currently smoking)], medical 
history and medication records. Anthropometric measurements included body weight and height were measured without shoes and in light clothing by well-trained endocrinology nurses. Body weight was measured using an electronic scale to the nearest $0.1 \mathrm{~kg}$ and height was measured using a metal column height meter to the nearest $0.1 \mathrm{~cm}$. WC was measured at the midpoint between the inferior costal margin and the iliac crest in the midaxillary line. Hip circumference was measured at the widest point over the buttocks, and the waist-hip ratio (WHR) was calculated as the ratio of waist to hip circumferences. BMI, used as a measure of general obesity, was calculated as weight $(\mathrm{kg}) /$ height $\left(\mathrm{m}^{2}\right)$. Blood pressure was measured using an electronic sphygmomanometer on the right or left arm after a 10-minute rest and the average of blood pressure was obtained on two assessments.

\section{Biomarker Measurements}

After a 10-12h-overnight fasting, blood samples were obtained in the early morning to measure the levels of blood profiles including FPG, fasting c-peptide (FCP), fasting insulin (FINS), glycated hemoglobin A1c (HbA1c), total cholesterol (TC), TG, HDL-C, lowdensity lipoprotein cholesterol (LDL-C), uric acid (UA) and serum creatinine (Scr). Then, the $100 \mathrm{~g}$ flour (steamed bread meal) test was performed in all subjects to assess the 2hPG, 2-hour postprandial C-peptide (2hCP) and 2-hour postprandial insulin ( $2 \mathrm{hINS}$ ) concentrations.

FPG and $2 \mathrm{hPG}$ were assayed by the glucose oxidase method, FCP and 2hCP were determined by chemiluminescence immunoassay. Lipid profiles were analyzed by enzymatic procedures using an autoanalyzer (Hitachi 747; Hitachi, Tokyo, Japan). HbAlc was determined by high-pressure liquid chromatography. UA was examined by enzymatic spectrophotometry. Homeostasis model assessment-insulin resistance (HOMA-IR) was calculated as fasting serum insulin $(\mathrm{mIU} / \mathrm{L}) \times$ FPG $(\mathrm{mmol} / \mathrm{L}) / 22.5 .^{32}$ HOMA-IR was used for further evaluation of insulin sensitivity. The eGFR was calculated following the formula: eGFR $(\mathrm{mL} / \mathrm{min} /$ $\left.1.73 \mathrm{~m}^{2}\right)=175 \times \operatorname{Scr}(\mathrm{mg} / \mathrm{dl})^{-1.234} \times$ age $^{-0.179} \times(1$ for men; 0.79 for women). ${ }^{33}$

\section{Measurement of Visceral Fat Area and Subcutaneous Fat Area}

VFA and subcutaneous fat area (SFA) of all participants with a 10 - to 12 -h fasting were measured by well-trained nurses.
The measurements of body site for VFA and SFA were measured at the level of umbilicus with a visceral fat analyzer (DUALSCAN HDS-2000, Omron Healthcare Kyoto, Japan) using the abdominal dual BIA method. ${ }^{19,20}$ The resultant values were based on the impedance indicated by the difference in electrical conductivity between fat and nonfat tissue. Two paths were used to measure the impedance. The first path (A) applied low-voltage alternating current to a total of four electrodes fixed on both sides of the hands and feet. The system detected a constant micro-current value and calculated the bio-impedance value generated when passing through the limbs, thus calculating the non-fat area. The second path (B) applied a weak electric current between the electrodes placed on the abdomen and also measured the impedance. SFA of the abdomen can be calculated according to the abdominal impedance. The cross-sectional area of the abdomen at the umbilical level was calculated by the "abdominal detection unit" in advance. Afterwards, VFA was calculated following the formula: cross-sectional area - the sum areas of $\mathrm{A}$ and $\mathrm{B}^{20}$

\section{Measurement of Common Carotid Intima-Media Thickness}

The intimal thickness of the carotid artery was measured with high-resolution B-mode ultrasound by experienced ultrasound experts. Patients were asked to take a supine position with their heads turning to the opposite side to fully expose the carotid artery. The intima-media thickness (IMT) on the distal wall of the common carotid artery on both sides was measured at about $1 \mathrm{~cm}$ from the carotid bifurcation. The greater value of the IMT of carotid artery from both sides was recorded as MaxIMT for analysis. Local carotid artery IMT greater than $1.5 \mathrm{~mm}$ was defined as carotid plaque formation. ${ }^{34}$

\section{Statistical Analysis}

Continuous variables with normal and skewed distributions were presented as mean and standard deviation (SD), and median (interquartile range). Continuous variables were analyzed by Student's $t$-test and MannWhitney $U$-test. Groups of categorical variables were compared by $\chi^{2}$ test. Spearman correlation was conducted to examine the relationship between VFA and MetS factors. Logistic regression was used to examine the association between VFA (continuous variables; independent variable) and MetS (categorical variable; dependent variable). Associations were investigated after adjusting for related factors (age, currently smoking, HOMA-IR, UA and 
currently using any kind of hypoglycemic medicines that might affect visceral fat accumulation [glucagon-like peptide-1 (GLP-1) agonists, thiazolidinediones (TZDs), glinides and sodium-dependent glucose transporters 2 (SGLT-2) inhibitors]). ${ }^{35-38}$ Receive operating characteristic (ROC) curve analysis was used to determine the diagnostic value of VFA for MetS in patients with T2D. The optimal cut-off values were obtained from the Youden index [maximum (sensitivity + specificity -1$)] .{ }^{39}$ Results were considered statistically significant at a twotailed level of 0.05 . Statistical analyses were performed with IBM SPSS Statistics version 20.0.

\section{Results}

\section{Clinical Characteristics of Study Individuals}

A total of 1017 T2D patients $(63.7 \%$ men) with a mean age of 54 years were finally included in the current study (Table 1). Around $75.6 \%(\mathrm{n}=769)$ patients were defined as to have MetS (MetS +). Mean values of age, BMI, BP, VFA, SFA, WHR, FPG, FINS, 2hINS, HOMA-IR, FCP, 2hCP, UA, TC, TG, LDL-C and maxIMT were significantly higher in patients with MetS compared to those without MetS. Regarding glucose-lowering medicines, only currently using any kind of hypoglycemic medicines that affect VFA was taken was significantly more in the group of patients with MetS $(\mathrm{P}=0.013)$.

\section{Relationship of Visceral Fat Area with the Risk Factors of Metabolic Syndrome}

Spearman correlation was performed to examine the relationship of VFA with metabolic parameters stratified by sex (Table 2). Age was only significantly associated with VFA in women $(\mathrm{r}=0.134, \mathrm{P}=0.012)$. VFA was positively correlated with all other parameters of anthropometry and biomarkers except for the negative correlation with HDL$\mathrm{C}$ in women, and the Spearman correlation coefficients of VFA with BMI, SFA HOMA-IR and uric acid were 0.729 , $0.687,0.343$ and 0.390 , respectively, while five parameters of MetS including FPG, 2hPG, HbA1c, TC and LDL-C were not associated with VFA in men.

The associations of MetS with VFA were further investigated by logistic regression (Table 3). VFA was associated with 1.02 (CI 1.02-1.03) and 1.03 (CI 1.02-1.05) higher odds of developing MetS in both men and women, respectively, after controlling for potential risk factors. However, only age was associated with higher odds of
MetS only in women $(\mathrm{OR}=1.05$, CI $1.02-1.08, \mathrm{P}<0.001)$ and uric acid was associated with higher odds of MetS only in men (OR=1.00, CI 1.00-1.01, $\mathrm{P}=0.034)$.

\section{The Optimal Cut-Off Values of Visceral Fat Area for the Metabolic Syndrome}

From the ROC curve analysis, the areas under the curve of ROC values of VFA predicting MetS were 0.752 (95\% CI $0.706-0.799, \mathrm{P}<0.001)$ in men and 0.785 (95\% CI 0.735-$0.836, \mathrm{P}<0.001$ ) in women (Figure 1). The optimal cut-off value of VFA was $84.7 \mathrm{~cm}^{2}$ (sensitivity: $74.7 \%$, specificity: $65.8 \%$ ) for men and $81.1 \mathrm{~cm}^{2}$ (sensitivity: $59.2 \%$, specificity: $88.0 \%$ ) for women (Table 4 ).

\section{Discussion}

In this study of a large clinical MMC study, the results of the current study showed that $75.6 \%$ T2D patients in Ningbo, China, were defined to have MetS. VFA and BMI were significantly associated with higher odds of MetS in both men and women. The optimal cut-off values of VFA predicting MetS among T2D patients was $84.7 \mathrm{~cm}^{2}$ in men and $81.1 \mathrm{~cm}^{2}$ in women.

To date, no study has been conducted on VFA cut-off values among Chinese T2D patients. The prevalence of MetS in our study is relatively higher than those from previous reports. ${ }^{40-42}$ A recent study involving 15,492 adult patients newly diagnosed with T2D in 46 tertiary care hospitals nationwide in China from 2015 to 2017 reported that the prevalence of MetS was $68.1 \%$ using the 2017 CDS definition. ${ }^{31,40}$ The higher prevalence of MetS in our study can be explained that majority of our regional patients are not newly diagnosed T2D patients. Likewise, the prevalence of MetS in our study is relatively higher than the same patients in Ethiopia $(66.7 \%)^{41}$ and in Korea (men: $46.9 \%$; women: $65.1 \%$ ) both using the US National Cholesterol Education Program Adult Treatment Panel III (NCEP ATP III) criteria. ${ }^{3,42}$

The guidelines from the CDS (2004) adapted BMI $\geq 25 \mathrm{~kg} / \mathrm{m}^{2}$ to define abdominal obesity predicting MetS among Chinese population. ${ }^{7}$ Additionally, International Diabetes Federation proposed a global diagnosis definition of MetS in 2005 and suggested the differential cut-off values of WC for defining abdominal obesity that reflected different races in each country. ${ }^{10}$ However, the body fat distribution of the Chinese population is characterized by abdominal fat accumulation. Evidence showed that Asians were more inclined to have obesity-related consequences 
Table I Baseline Clinical Characteristics of Patients with Type 2 Diabetes

\begin{tabular}{|c|c|c|c|c|}
\hline & Total $N=1017$ & MetS (-) N=248 & MetS (+) N=769 & $P$ value \\
\hline Male, n (\%) & $648(63.7)$ & $15 \mid(60.9)$ & $497(64.6)$ & 0.287 \\
\hline Age (years) & $54(47-6 I)$ & $53(45-59)$ & $55(47-62)$ & 0.022 \\
\hline Currently smoking, n (\%) & $254(24.9)$ & $66(26.6)$ & I88 (24.4) & 0.493 \\
\hline \multicolumn{5}{|l|}{ Anthropometry and biomarkers } \\
\hline SBP $(\mathrm{mmHg})$ & $132.95 \pm 18.06$ & $125.05 \pm 15.23$ & $135.49 \pm 18.17$ & $<0.001$ \\
\hline $\mathrm{DBP}(\mathrm{mmHg})$ & $78.56 \pm 11.02$ & $75.05 \pm 10.16$ & $79.7 .0 \pm 11.04$ & $<0.001$ \\
\hline Weight (kg) & $69.23 \pm 12.82$ & $62.07 \pm 10.92$ & $71.54 \pm 12.54$ & $<0.001$ \\
\hline BMI $\left(\mathrm{kg} / \mathrm{m}^{2}\right)$ & $25.23 \pm 3.64$ & $22.86 \pm 2.84$ & $26.00 \pm 3.52$ & $<0.001$ \\
\hline Waist circumference $(\mathrm{cm})$ & $89.03 \pm 9.94$ & $81.62 \pm 8.70$ & $91.42 \pm 9.11$ & $<0.001$ \\
\hline Hip circumference $(\mathrm{cm})$ & $95.06 \pm 7.19$ & $91.23 \pm 6.60$ & $96.29 \pm 6.93$ & $<0.001$ \\
\hline WHR & $0.94 \pm 0.07$ & $0.90 \pm 0.10$ & $0.94 \pm 0.06$ & $<0.001$ \\
\hline VFA $\left(\mathrm{cm}^{2}\right)$ & $93.82 \pm 40.06$ & $68.58 \pm 34.65$ & $101.98 \pm 38.28$ & $<0.001$ \\
\hline SFA $\left(\mathrm{cm}^{2}\right)$ & $|79.4| \pm 62.88$ & $|42.79 \pm 49.1|$ & $191.23 \pm 62.32$ & $<0.001$ \\
\hline FPG (mmol/L) & $8.57 \pm 2.94$ & $8.21 \pm 3.07$ & $8.69 \pm 2.89$ & 0.027 \\
\hline $2 \mathrm{hPG}(\mathrm{mmol} / \mathrm{L})$ & $13.63 \pm 4.97$ & $|3.54 \pm 5.5|$ & $13.66 \pm 4.77$ & 0.742 \\
\hline FINS (mIU/L) & $11.30(6.26-30.17)$ & $7.42(4.30-18.90)$ & $12.30(7.43-34.88)$ & $<0.001$ \\
\hline 2hINS (mIU/L) & $38.52(21.44-92.32)$ & $28.45(15.42-66.45)$ & $43.23(22.97-104.5)$ & $<0.001$ \\
\hline HbAlc (\%) & $7.70(6.50-9.20)$ & $7.40(6.40-9.20)$ & $7.80(6.60-9.20)$ & 0.146 \\
\hline HOMA-IR & $4.11(2.19-11.49)$ & $2.62(1.44-6.97)$ & $4.84(2.60-13.15)$ & $<0.001$ \\
\hline $\mathrm{FCP}(\mu \mathrm{g} / \mathrm{L})$ & $1.73(1.00-2.53)$ & $1.32(0.73-1.87)$ & $1.92(1.11-2.73)$ & $<0.001$ \\
\hline $2 \mathrm{hCP}(\mu \mathrm{g} / \mathrm{L})$ & $4.08(2.42-6.04)$ & $3.41(1.96-4.92)$ & $4.26(2.63-6.35)$ & $<0.001$ \\
\hline Uric acid (mmol/L) & $333.86 \pm 85.01$ & $303.36 \pm 80.06$ & $343.70 \pm 84.26$ & $<0.001$ \\
\hline Total cholesterol $(\mathrm{mmol} / \mathrm{L})$ & $4.52 \pm 1.24$ & $4.17 \pm 1.08$ & $4.63 \pm 1.26$ & $<0.001$ \\
\hline Triglycerides (mmol/L) & $1.43(1.00-2.14)$ & $1.05(0.79-1.37)$ & $1.70(1.12-2.36)$ & $<0.001$ \\
\hline HDL-C (mmol/L) & $1.16 \pm 0.29$ & $1.16 \pm 0.35$ & $1.15 \pm 0.28$ & 0.829 \\
\hline LDL-C (mmol/L) & $4.52 \pm 1.24$ & $2.68 \pm 0.80$ & $2.93 \pm 0.89$ & $<0.001$ \\
\hline Max IMT (mm) & $0.80(0.60-1.00)$ & $0.80(0.60-0.90)$ & $0.80(0.60-1.00)$ & 0.032 \\
\hline Carotid plaque, n (\%) & $365(35.9)$ & $70(28.2)$ & $295(38.4)$ & 0.006 \\
\hline Duration of diabetes (years) & $6.58(2.50-12.00)$ & $6.50(2.10-12.06)$ & $6.6(2.75-12.00)$ & 0.363 \\
\hline \multicolumn{5}{|l|}{ Glucose-lowering medication treatments, n (\%) } \\
\hline Insulin & $338(33.2)$ & $89(35.9)$ & $249(32.4)$ & 0.346 \\
\hline TZDs & $25(2.5)$ & $5(2.0)$ & $20(2.6)$ & 0.605 \\
\hline Sulfonylureas & $326(32.1)$ & $88(35.5)$ & $238(30.9)$ & 0.210 \\
\hline Glinides & $107(10.5)$ & $23(9.3)$ & $84(10.9)$ & 0.537 \\
\hline GLP-I agonists & $135(13.1)$ & $33(12.8)$ & $102(13.3)$ & 0.930 \\
\hline Biguanides & $683(67.2)$ & $166(66.9)$ & $517(67.2)$ & 0.993 \\
\hline Alpha-Gls & $367(36.1)$ & $85(34.3)$ & $282(36.7)$ & 0.544 \\
\hline DPP4 inhibitors & $287(28.2)$ & $69(27.8)$ & $218(28.3)$ & 0.937 \\
\hline SGLT-2 inhibitors & $80(7.9)$ & $21(8.5)$ & $59(7.7)$ & 0.788 \\
\hline $\begin{array}{l}\text { Currently using any kind of hypoglycemic medicines that affect } \\
\text { VFA }^{\ddagger}\end{array}$ & $681(70.9)$ & $54(22.6)$ & $280(31.1)$ & 0.013 \\
\hline
\end{tabular}

Notes: Data represent mean standard deviation or median (interquartile range $25-75 \%$ ). ${ }^{\ddagger}$ Currently using any kind of hypoglycemic medicines that affect visceral fat accumulation included GLP-I agonists, TZDs, glinides and SGLT-2 inhibitors.

Abbreviations: SBP, systolic blood pressure; DBP, diastolic blood pressure; BMI, body mass index; WHR, waist-hip ratio; VFA, visceral fat area; SFA, subcutaneous fat area; FPG, fasting plasma glucose; 2hPG, 2-hour postprandial plasma glucose; FINS, fasting plasma insulin, 2hINS, 2-hour postprandial plasma insulin; HbAlc, glycated hemoglobin Alc; HOMA-IR, homeostasis model assessment for insulin resistance; FCP, fasting c-peptide; 2hCP, 2-hour postprandial c-peptide; HDL-C, high-density lipoprotein cholesterol; LDL-C, low-density lipoprotein cholesterol; max IMT, max common carotid intima-media thickness. TZD, thiazolidinedione; GLP-I agonists, glucagon-like peptide-I agonists; alpha-Gls, alpha-glucosidase inhibitor; DPP4 inhibitors, dipeptidyl peptidase-4 inhibitors; SGLT-2 inhibitors, sodium-dependent glucose transporters 2 inhibitors. 
Table 2 Spearman Correlation Between VFA and Metabolic Parameters

\begin{tabular}{|c|c|c|c|c|}
\hline & \multicolumn{4}{|c|}{ VFA $\left(\mathrm{cm}^{2}\right)$} \\
\hline & \multicolumn{2}{|c|}{ Men $(n=648)$} & \multicolumn{2}{|c|}{ Women $(n=369)$} \\
\hline & $\boldsymbol{r}$ & $P$ value & $r$ & $P$ value \\
\hline Age (years) & 0.042 & 0.291 & 0.134 & 0.012 \\
\hline $\mathrm{SBP}(\mathrm{mmHg})$ & 0.309 & $<0.001$ & 0.246 & $<0.001$ \\
\hline $\mathrm{DBP}(\mathrm{mmHg})$ & 0.215 & $<0.001$ & 0.157 & 0.003 \\
\hline BMI $\left(\mathrm{kg} / \mathrm{m}^{2}\right)$ & 0.659 & $<0.001$ & 0.729 & $<0.001$ \\
\hline SFA $\left(\mathrm{cm}^{2}\right)$ & 0.665 & $<0.001$ & 0.687 & $<0.001$ \\
\hline FPG (mmol/L) & 0.049 & 0.224 & 0.177 & $<0.001$ \\
\hline 2hPG (mmol/L) & 0.021 & 0.607 & 0.116 & $<0.001$ \\
\hline FINS (mlU/L) & 0.337 & $<0.001$ & 0.328 & $<0.001$ \\
\hline 2hINS (mIU/L) & 0.267 & $<0.001$ & 0.216 & $<0.001$ \\
\hline HbAlc (\%) & -0.016 & 0.692 & 0.211 & $<0.001$ \\
\hline HOMA-IR & 0.325 & $<0.001$ & 0.343 & $<0.001$ \\
\hline $\mathrm{FCP}(\mu \mathrm{g} / \mathrm{L})$ & 0.310 & $<0.001$ & 0.286 & $<0.001$ \\
\hline $2 \mathrm{hCP}(\mu \mathrm{g} / \mathrm{L})$ & 0.206 & $<0.001$ & 0.148 & 0.006 \\
\hline Uric acid (mmol/L) & 0.235 & $<0.001$ & 0.390 & $<0.001$ \\
\hline $\begin{array}{l}\text { Total cholesterol } \\
(\mathrm{mmol} / \mathrm{L})\end{array}$ & 0.032 & 0.420 & 0.045 & $<0.001$ \\
\hline Triglycerides (mmol/L) & 0.337 & $<0.001$ & 0.384 & $<0.001$ \\
\hline HDL-C (mmol/L) & -0.215 & $<0.001$ & $-0.24 I$ & $<0.001$ \\
\hline LDL-C (mmol/L) & 0.012 & 0.765 & 0.116 & 0.029 \\
\hline
\end{tabular}

Abbreviations: SBP, systolic blood pressure; DBP, diastolic blood pressure; BMI, body mass index; VFA, visceral fat area; SFA, subcutaneous fat area; FPG, fasting plasma glucose; 2hPG, 2-hour postprandial plasma glucose; FINS, fasting plasma insulin, 2hINS, 2-hour postprandial insulin; HbAlc, glycated hemoglobin Alc; FCP, fasting c-peptide; $2 \mathrm{hCP}$, 2-hour postprandial c-peptide; HDL-C, high-density lipoprotein cholesterol; LDL-C, low-density lipoprotein cholesterol.

at a lower BMI or a lower WC because of higher body fat mass deposition, compared to Caucasians. ${ }^{43,44}$ Around $14 \%$ abdominal fat mass deposition was reported in Chinese, although their BMI was lower than cut-off value of $25 \mathrm{~kg} / \mathrm{m}^{2}{ }^{45} \mathrm{VFA}$ is suggested to be a more accurate measurement than both WC and BMI for defining abdominal obesity. ${ }^{14-17}$ Comparable results have been reported in China on healthy Chinese population, VFA $\geq 80 \mathrm{~cm}^{2}$ was proposed as an optimal cut-off value for predicting MetS and WC of $90 \mathrm{~cm}$ for men and $85 \mathrm{~cm}$ for women proposed as the cut-off values for the diagnosis of abdominal obesity in China. ${ }^{16}$ A 7.8 -year follow-up
Table 3 Logistic Regression Analysis of Associated with Met $\varsigma^{\S}$ in Patients with Type 2 Diabetes

\begin{tabular}{|c|c|c|c|c|}
\hline & \multicolumn{2}{|c|}{ Men $(n=648)$} & \multicolumn{2}{|c|}{ Women $(n=369)$} \\
\hline & $\begin{array}{l}\text { Odds Ratio } \\
(95 \% \mathrm{Cl})\end{array}$ & $P$ value & $\begin{array}{l}\text { Odds Ratio } \\
(95 \% \mathrm{Cl})\end{array}$ & $P$ value \\
\hline Age (year) & $1.01(0.99-1.03)$ & 0.400 & $1.05(1.02-1.08)$ & $<0.001$ \\
\hline VFA $\left(\mathrm{cm}^{2}\right)$ & $1.02(1.02-1.03)$ & $<0.001$ & $1.03(1.02-1.05)$ & $<0.001$ \\
\hline $\begin{array}{l}\text { Uric acid } \\
(\mathrm{mmol} / \mathrm{L})\end{array}$ & $1.00(1.00-1.01)$ & 0.034 & $1.00(0.99-1.01)$ & 0.094 \\
\hline HOMA-IR & $1.00(0.99-1.01)$ & 0.618 & $1.02(0.99-1.04)$ & 0.138 \\
\hline $\begin{array}{l}\text { Currently } \\
\text { smoking }^{\S}\end{array}$ & $1.33(0.85-2.09)$ & 0.210 & $0.52(0.24-1.12)$ & 0.092 \\
\hline $\begin{array}{l}\text { Currently using } \\
\text { any kind of } \\
\text { hypoglycemic } \\
\text { medicines that } \\
\text { affect VFA }\end{array}$ & $0.88(0.55-1.40)$ & 0.577 & $1.56(0.84-2.87)$ & 0.156 \\
\hline
\end{tabular}

Notes: ${ }^{\S}$ MetS (-), currently no smoking and currently no hypoglycemic medicines treatment [human glucagon-like peptide-I (GLP-I) agonists, thiazolidinediones (TZDs), glinides and sodium-dependent glucose transporters 2 (SGLT-2) inhibitors] are references in the models.

Abbreviations: $\mathrm{Cl}$, confidence interval; VFA, visceral fat area; HOMA-IR, homeostasis model assessment for insulin resistance.

study, conducted on healthy adults, indicated that abdominal obesity in an independent risk factor causing T2D and VFA $\geq 90 \mathrm{~cm}^{2}$ was proposed as the cut-off values to define

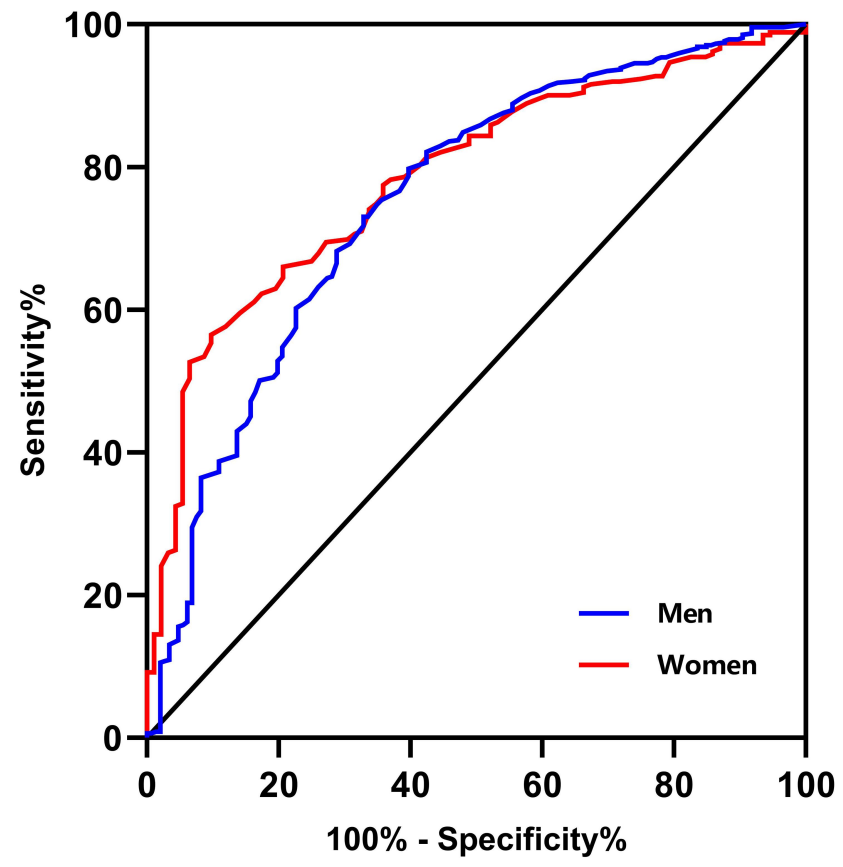

Figure I ROC curves for cut-off value of VFA to predict MetS. In men: area under the curve $=0.752,95 \% \mathrm{Cl} 0.706-0.799, \mathrm{P}<0.00 \mathrm{I}$. Sensitivity and specificity at a VFA of $84.7 \mathrm{~cm}^{2}$ were $74.7 \%$ and $65.8 \%$, respectively. In women: area under the curve $=0.785,95 \% \mathrm{Cl}$ $0.735-0.836, P<0.001$. Sensitivity and specificity at a VFA of $81.1 \mathrm{~cm}^{2}$ were $59.2 \%$ and $88.0 \%$, respectively. 
Table 4 Cut-Off Values of VFA to Identify MetS in Patients with Type 2 Diabetes

\begin{tabular}{|l|l|l|l|}
\hline Sex & Cut-Off Values & Sensitivity (\%) & Specificity (\%) \\
\hline Men & 84.7 & 74.7 & 65.8 \\
Women & 81.1 & 59.2 & 88.0 \\
\hline
\end{tabular}

abdominal obesity. ${ }^{46}$ In addition, VFA cut-off value of $100 \mathrm{~cm}^{2}$ was proposed for Japanese adults to define abdominal obesity indicating the risk of obesity-related diseases with NCEP-ATP III definition. ${ }^{3,15} \mathrm{Kim}$ et al reported that the optimal VFA using NCEP-ATP III definition associated with an increased risk of obesity-related diseases was $103.8 \mathrm{~cm}^{2}$ in Korean adults in both genders. $^{3,17}$ Our VFA cut-off values were much lower than the results from Japanese and Korean studies. It might be caused by the various definitions of MetS.

Considering the gender-specific cut-off values for VFA in our study, VFA was significantly correlated with risk factors of T2D, especially in women. Logistic regression model, as expected, illustrated VFA indicated a significantly increased risk of MetS in patients with T2D. Previous studies suggested that the VFA cutoff value was associated with MetS. ${ }^{16,17}$ The mechanisms between VFA, and MetS and various components are complex and unclear yet. The possible mechanisms might be that visceral fat can secrete various hormones and inflammatory cytokines, such as tumor necrosis factora and interleukin-6, which can affect the insulin sensitivity of peripheral tissues. ${ }^{47,48}$ With a higher rate of lipolysis of visceral fat than subcutaneous fat, decomposed products of VFA, such as free fatty acids and glycerin, directly enter the liver through the portal vein circulation, stimulating liver lipoprotein synthesis and gluconeogenesis, reducing liver insulin removal, and increasing blood glucose and insulin resistance. ${ }^{49,50}$ Thus, excessive visceral fat accumulation is more likely to induce diabetes, MetS and CVD. Our results also confirmed that insulin resistance and abdominal obesity were important features of MetS in diabetes. Moreover, age was found to be associated with high odds of MetS in women in our study. Recent studies indicated that age is a key factor playing a role in developing MetS. ${ }^{51,52}$ No cut-off value of VFA has been standardized among Chinese T2D patients yet. Lee et al ${ }^{52}$ and his colleagues reported that cut-off values increased with age, particularly among women, which in line with our finding. Due to post-menopause, women tend to be sensitive to accumulate fat mass in waist area. ${ }^{53}$ With no stratification of age, it might explain the lower sensitivity in our study.

The present study has some limitations. First, causality between VFA and MetS cannot be inferred according to the nature of cross-sectional study design. Second, VFA results might be affected by gender, age, medication, and the shape of the human body or the distribution of water in the patients' body. Then, due to different lifestyles and regional patients from Ningbo, China, thus, the findings cannot be generalized to the general Chinese population. The last but not least, considering the small sample size, subgroup of age could not be analyzed.

\section{Conclusions}

The present study is the first study reporting the genderspecific optimal cut-off values of VFA for T2D patients in Ningbo, China, and predicted the optimal cut-off values of VFA be $84.7 \mathrm{~cm}^{2}$ in men and $81.1 \mathrm{~cm}^{2}$ in women. Our results demonstrated that MetS was common in T2D patients. VFA was a strong risk factor for the development of the MetS among T2D patients. Therefore, T2D patients with a VFA over the optimal cut-off values should be closely monitored for the development of MetS, and further prospective studies are needed to validate the relationship between the suggested VFA cut points and MetS in people with T2D.

\section{Data Sharing Statement}

The data that support the findings of this study are available from the corresponding author upon reasonable request.

\section{Ethics Statement}

The study was ethically approved by the Ethics Committee of Ningbo First Hospital, China (Ethics Approval No. 2019-R057) and followed the Declaration of Helsinki.

\section{Acknowledgments}

The authors thank all the patients involved in the study. We thank Ningbo first hospital for their support of the research project. We thank School of Economics, Faculty of Humanities and Social Sciences, University of Nottingham Ningbo China to support this research collaboration.

\section{Funding}

This study was supported by Medical Health Science and Technology Project of Zhejiang Provincial Health Commission (Grant No. 2019331427) and Major 
Program of Social Development of Ningbo Science and Technology Bureau (Grant No. 2019C50094) and Ningbo Science \& Technology Bureau (Grant No. 2019A610391).

\section{Disclosure}

The authors declared no conflicts of interest for this work.

\section{References}

1. Wilson PW, D'Agostino RB, Parise H, Sullivan L, Meigs JB. Metabolic syndrome as a precursor of cardiovascular disease and type 2 diabetes mellitus. Circulation. 2005;112(20):3066-3072. doi:10.1161/CIRCULATIONAHA.105.539528

2. Meigs JB, Rutter MK, Sullivan LM, et al. Impact of insulin resistance on risk of type 2 diabetes and cardiovascular disease in people with metabolic syndrome. Diabetes Care. 2007;30(5):1219-1225. doi: $10.2337 / \mathrm{dc} 06-2484$

3. Executive Summary of the Third Report of The National Cholesterol Education Program (NCEP). Expert panel on detection, evaluation, and treatment of high blood cholesterol in adults (Adult Treatment Panel III). JAMA. 2001;285(19):2486-2497. doi:10.1001/jama.285.19.2486

4. Grundy SM, Brewer HB Jr, Cleeman JI, et al. Definition of metabolic syndrome: Report of the National Heart, Lung, and Blood Institute/ American Heart Association conference on scientific issues related to definition. Circulation. 2004;109(3):433-438. doi:10.1161/01. CIR.0000111245.75752.C6

5. Xi B, He D, Hu Y, Zhou D. Prevalence of metabolic syndrome and its influencing factors among the Chinese adults: the China health and nutrition survey in 2009. Prev Med. 2013;57(6):867-871. doi:10.1016/j.ypmed.2013.09.023

6. Lan Y, Mai Z, Zhou S, et al. Prevalence of metabolic syndrome in China: an up-dated cross-sectional study. PLoS One. 2018;13(4): e0196012. doi:10.1371/journal.pone.0196012

7. Metabolic Syndrome Research Cooperative Group, Diabetes Branch of Chinese Medical Association. Suggestions on metabolic syndrome from Chinese society of diabetes mellitus. Chin J Diabetes. 2004;12 (3):156-161.

8. Carr DB, Utzschneider KM, Hull RL, et al. Intra-abdominal fat is a major determinant of the National Cholesterol Education Program Adult Treatment Panel III criteria for the metabolic syndrome. Diabetes. 2004;53(8):2087-2094. doi:10.2337/diabetes.53.8.2087

9. Fujimoto WY, Bergstrom RW, Boyko EJ, et al. Visceral adiposity and incident coronary heart disease in Japanese-American men. The 10-year follow-up results of the Seattle Japanese-American Community Diabetes Study. Diabetes Care. 1999;22 (11):1808-1812. doi:10.2337/diacare.22.11.1808

10. Alberti KG, Zimmet P, Shaw J. metabolic syndrome-a new worldwide definition. a consensus statement from the international diabetes federation. Diabetes Med. 2006;23(5):469-480. doi:10.1111/j.14645491.2006.01858.x

11. Nakamura T, Tokunaga K, Shimomura I, et al. Contribution of visceral fat accumulation to the development of coronary artery disease in non-obese men. Atherosclerosis. 1994;107(2):239-246. doi:10.1016/0021-9150(94)90025-6

12. Fox CS, Massaro JM, Hoffmann U, et al. Abdominal visceral and subcutaneous adipose tissue compartments: association with metabolic risk factors in the Framingham Heart Study. Circulation. 2007;116(1):39-48. doi:10.1161/CIRCULATIONAHA.106.675355

13. Wang Y, Ma X, Zhou M, et al. Contribution of visceral fat accumulation to carotid intima-media thickness in a Chinese population. Int $J$ Obes (Lond). 2012;36(9):1203-1208. doi:10.1038/ijo.2011.222
14. Oka R, Kobayashi J, Yagi K, et al. Reassessment of the cutoff values of waist circumference and visceral fat area for identifying Japanese subjects at risk for the metabolic syndrome. Diabetes Res Clin Pract. 2008;79(3):474-481. doi:10.1016/j.diabres.2007.10.016

15. Examination Committee of Criteria for 'Obesity Disease' in Japan; Japan Society for the Study of Obesity. New criteria for 'obesity disease' in Japan. Circ J. 2002;66(11):987-992. doi:10.1253/ circj. 66.987

16. Bao Y, Lu J, Wang C, et al. Optimal waist circumference cutoffs for abdominal obesity in Chinese. Atherosclerosis. 2008;201(2):378-384. doi:10.1016/j.atherosclerosis.2008.03.001

17. Kim JA, Choi CJ, Yum KS. Cut-off values of visceral fat area and waist circumference: diagnostic criteria for abdominal obesity in a Korean population. J Korean Med Sci. 2006;21(6):1048-1053. doi:10.3346/jkms.2006.21.6.1048

18. Yoshizumi T, Nakamura T, Yamane M, et al. Abdominal fat: standardized technique for measurement at CT. Radiology. 1999;211 (1):283-286. doi:10.1148/radiology.211.1.r99ap15283

19. Enomoto M, Adachi H, Fukami A, et al. A useful tool as a medical checkup in a general population-bioelectrical impedance analysis. Front Cardiovasc Med. 2017;4:3. doi:10.3389/fcvm.2017.00003

20. Park KS, Lee DH, Lee J, et al. Comparison between two methods of bioelectrical impedance analyses for accuracy in measuring abdominal visceral fat area. J Diabetes Complications. 2016;30(2):343-349. doi:10.1016/j.jdiacomp.2015.10.014

21. Ryo M, Maeda K, Onda T, et al. A new simple method for the measurement of visceral fat accumulation by bioelectrical impedance. Diabetes Care. 2005;28(2):451-453. doi:10.2337/diacare.28.2.451

22. Björntorp P. "Portal" adipose tissue as a generator of risk factors for cardiovascular disease and diabetes. Arteriosclerosis. 1990;10 (4):493-496.

23. Lee JJ, Pedley A, Hoffmann U, Massaro JM, Fox CS. Association of changes in abdominal fat quantity and quality with incident cardiovascular disease risk factors. $J$ Am Coll Cardiol. 2016;68 (14):1509-1521. doi:10.1016/j.jacc.2016.06.067

24. Isomaa B, Almgren P, Tuomi T, et al. Cardiovascular morbidity and mortality associated with the metabolic syndrome. Diabetes Care. 2001;24(4):683-689. doi:10.2337/diacare.24.4.683

25. Martínez-Larrad MT, Corbatón-Anchuelo A, Fernández-Pérez C, Lazcano-Redondo Y, Escobar-Jiménez F, Serrano-Ríos M. Metabolic syndrome, glucose tolerance categories and the cardiovascular risk in Spanish population. Diabetes Res Clin Pract. 2016;114:23-31. doi:10.1016/j.diabres.2016.02.003

26. Malik S, Wong ND, Franklin SS, et al. Impact of the metabolic syndrome on mortality from coronary heart disease, cardiovascular disease, and all causes in United States adults. Circulation. 2004;110 (10):1245-1250. doi:10.1161/01.CIR.0000140677.20606.0E

27. Wang J, Ruotsalainen S, Moilanen L, Lepistö P, Laakso M, Kuusisto J. The metabolic syndrome predicts cardiovascular mortality: a 13-year follow-up study in elderly non-diabetic Finns. Eur Heart J. 2007;28(7):857-864. doi:10.1093/eurheartj/eh1524

28. Lin Y, Ying YY, Li SX, Wang SJ, Gong QH, Li H. Association between alcohol consumption and metabolic syndrome among Chinese adults. Public Health Nutr. 2020;1-23. doi:10.1017/ S1368980020004449

29. Zhang Y, Wang W, Ning G. Metabolic management center: an innovation project for the management of metabolic diseases and complications in China. J Diabetes. 2019;11(1):11-13. doi:10.1111/17530407.12847

30. Alberti KG, Zimmet PZ. Definition, diagnosis and classification of diabetes mellitus and its complications. Part 1: diagnosis and classification of diabetes mellitus provisional report of a WHO consultation. Diabetes Med. 1998;15(7):539-553. doi:10.1002/ (SICI)1096-9136(199807)15:7<539::AID-DIA668>3.0.CO;2-S 
31. Chinese Diabetes Society. Guidelines for prevention and treatment of type 2 diabetes in Chinese (2017 edition). Chin J Diabetes Mellit. 2018;10(1):4-67.

32. Matthews DR, Hosker JP, Rudenski AS, Naylor BA, Treacher DF, Turner RC. Homeostasis model assessment: insulin resistance and beta-cell function from fasting plasma glucose and insulin concentrations in man. Diabetologia. 1985;28(7):412-419. doi:10.1007/ BF00280883

33. Ma YC, Zuo L, Chen JH, et al. Modified glomerular filtration rate estimating equation for Chinese patients with chronic kidney disease. $J$ Am Soc Nephrol. 2006;17(10):2937-2944. doi:10.1681/ASN.200 6040368

34. Ultrasound Branch of Chinese Medical Doctor Association. Guidelines for ultrasound vascular examination. Chin J Ultrasound Imaging. 2009;18(10):911-920.

35. Jendle J, Nauck MA, Matthews DR, et al. Weight loss with liraglutide, a once-daily human glucagon-like peptide-1 analogue for type 2 diabetes treatment as monotherapy or added to metformin, is primarily as a result of a reduction in fat tissue. Diabetes Obes Metab. 2009;11(12):1163-1172. doi:10.1111/j.1463-1326.2009.01158.x

36. Kodama N, Tahara N, Tahara A, et al. Effects of pioglitazone on visceral fat metabolic activity in impaired glucose tolerance or type 2 diabetes mellitus. J Clin Endocrinol Metab. 2013;98(11):4438-4445. doi:10.1210/jc.2013-2920

37. Mori Y, Mamori S, Tajima N. Weight loss-associated changes in acute effects of nateglinide on insulin secretion after glucose loading: results of glucose loading on 2 consecutive days. Diabetes Obes Metab. 2005;7(2):182-188. doi:10.1111/j.1463-1326.2004.00384.x

38. Bolinder J, Ljunggren Ö, Kullberg J, et al. Effects of dapagliflozin on body weight, total fat mass, and regional adipose tissue distribution in patients with type 2 diabetes mellitus with inadequate glycemic control on metformin. J Clin Endocrinol Metab. 2012;97 (3):1020-1031. doi:10.1210/jc.2011-2260

39. Perkins NJ, Schisterman EF. The inconsistency of "optimal" cutpoints obtained using two criteria based on the receiver operating characteristic curve. Am J Epidemiol. 2006;163(7):670-675. doi:10.1093/aje/kwj063

40. Li X, Cao C, Tang X, et al. Prevalence of metabolic syndrome and its determinants in newly-diagnosed adult-onset diabetes in china: a multi-center, cross-sectional survey. Front Endocrinol (Lausanne). 2019;10:661. doi:10.3389/fendo.2019.00661

41. Birarra MK, Gelayee DA. Metabolic syndrome among type 2 diabetic patients in Ethiopia: a cross-sectional study. BMC Cardiovasc Disord. 2018;18(1):149. doi:10.1186/s12872-018-0880-7
42. Kim WY, Kim JE, Choi YJ, Huh KB. Nutritional risk and metabolic syndrome in Korean type 2 diabetes mellitus. Asia Pac J Clin Nutr. 2008;17(Suppl 1):47-51.

43. Unwin N, Harland J, White $\mathrm{M}$, et al. Body mass index, waist circumference, waist-hip ratio, and glucose intolerance in Chinese and Europid adults in Newcastle, UK. J Epidemiol Community Health. 1997;51(2):160-166. doi:10.1136/jech.51.2.160

44. Deurenberg-Yap M, Chew SK, Deurenberg P. Elevated body fat percentage and cardiovascular risks at low body mass index levels among Singaporean Chinese, Malays and Indians. Obes Rev. 2002;3 (3):209-215. doi:10.1046/j.1467-789X.2002.00069.x

45. Jia WP, Lu JX, Xiang KS, Bao YQ, Lu HJ, Chen L. Prediction of abdominal visceral obesity from body mass index, waist circumference and waist-hip ratio in Chinese adults: receiver operating characteristic curves analysis. Biomed Environ Sci. 2003;16(3):206-211.

46. Ye Y, Bao Y, Hou X, et al. Identification of waist circumference cutoffs for abdominal obesity in the Chinese population: a 7.8-year follow-up study in the Shanghai urban area. Int $J$ Obes (Lond). 2009;33(9):1058-1062. doi:10.1038/ijo.2009.134

47. Galic S, Oakhill JS, Steinberg GR. Adipose tissue as an endocrine organ. Mol Cell Endocrinol. 2010;316(2):129-139. doi:10.1016/j. mce.2009.08.018

48. Pou KM, Massaro JM, Hoffmann U, et al. Visceral and subcutaneous adipose tissue volumes are cross-sectionally related to markers of inflammation and oxidative stress: the Framingham Heart Study. Circulation. 2007;116(11):1234-1241. doi:10.1161/CIRCULATI ONAHA.107.710509

49. Funahashi T, Matsuzawa Y. Metabolic syndrome: clinical concept and molecular basis. Ann Med. 2007;39(7):482-494. doi:10.1080/ 07853890701491026

50. Frayn KN. Visceral fat and insulin resistance-causative or correlative? $\mathrm{Br}$ J Nutr. 2000;83(Suppl 1):S71-S77. doi:10.1017/S0007114500000982

51. Hayashi T, Boyko EJ, McNeely MJ, Leonetti DL, Kahn SE, Fujimoto WY. Minimum waist and visceral fat values for identifying Japanese Americans at risk for the metabolic syndrome. Diabetes Care. 2007;30(1):120-127. doi:10.2337/dc06-0739

52. Lee A, Kim YJ, Oh SW, et al. Cut-off values for visceral fat area identifying korean adults at risk for metabolic syndrome. Korean J Fam Med. 2018;39(4):239-246. doi:10.4082/kjfm.17.0099

53. Toth MJ, Tchernof A, Sites CK, Poehlman ET. Menopause-related changes in body fat distribution. Ann $N$ Y Acad Sci. 2000;904:502-506. doi:10.1111/j.1749-6632.2000.tb06506.x

Diabetes, Metabolic Syndrome and Obesity: Targets and Therapy

Dovepress

\section{Publish your work in this journal}

Diabetes, Metabolic Syndrome and Obesity: Targets and Therapy is an international, peer-reviewed open-access journal committed to the rapid publication of the latest laboratory and clinical findings in the fields of diabetes, metabolic syndrome and obesity research. Original research, review, case reports, hypothesis formation, expert opinion and commentaries are all considered for publication. The manuscript management system is completely online and includes a very quick and fair peer-review system, which is all easy to use. Visit http://www.dovepress.com/testimonials.php to read real quotes from published authors. 